\title{
A Review on Energy Storage Systems for Mitigation Power Fluctuations in Wind Turbine based Power System
}

\author{
Sarvesh Garg \\ M.Tech Scholar, Electrical Engineering Department \\ BUEST, Baddi, Himachal Pradesh, India
}

\author{
Geena Kalpesh \\ Professor, Electrical Engineering Department, \\ BUEST, Baddi, Himachal Pradesh, India
}

\section{ABSTRACT}

Wind energy is in exhaustible renewable. Unlike conventional fossil fuels, wind energy is clean, abundant energy that will be available for future generations. However, wind speed is a highly stochastic component which can deviate very quickly. Output power of the wind energy conversion system (WECS) is proportional to the cube of wind speed, which causes the output power fluctuation of the wind turbine. The power fluctuation causes frequency fluctuation and voltage flicker inside the power grid. In order to reduce the power fluctuation, various approaches have been proposed in the last decades. This article deals with the review of several power smoothing strategies for the WECS. Power smoothing methods of the WECS are primarily separated in to two categories such as energy storage based power smoothing method and without energy storage based power smoothing method. The main objectives of this paper are to introduce operating principles for different power smoothing methods.

KEYWORD: Wind Energy Conversion System; Power smoothening system; Energy storage system; Pitch angel control

\section{INTRODUCTION}

World primary energy consumption rose by $2.5 \%$ in 2011 , roughly in line with the 10 -year average. In 2011 energy supply by power source was coal $41 \%$, gas $22 \%$, oil $4 \%$, fossil fuels $67 \%$, nuclear $13 \%$, and renewable energies (hydro, solar, wind, geothermal power, bio-fuels etc.) $20 \%$ [1]. Fossil fuels are nonrenewable resources because they take millions of years to form, and reserves are being depleted much faster than the new ones are being made [2]. The burning of fossil fuels produces around 21.3 billion tones (21.3 giga-tones) of carbon dioxide (CO2) per year, but it is estimated that natural procedures can only soak up about half of that amount, so there is a net increase of 10.65 billion tones of atmospheric carbon dioxide per year [3]. Carbon dioxide is one of the greenhouse gases that increases radioactive forcing and contributes to global warming, causing the average surface temperature of the world to rise in response, which the vast majority of climate scientists concur will cause major adverse effects.

The nuclear energy is an unreliable power source and it poses many threats to the people and the environment. These threats include health risks and environmental damage from uranium mining, processing and transport, the risk of nuclear weapons proliferation or sabotage, and the unsolved problem of radioactive nuclear waste [4]; [5]. Following an earthquake, tsunami, and the failure of cooling systems at Fukushima I Nuclear Power Plant and issues concerning other nuclear facilities in Japan on March 11, 2011, a nuclear emergency was declared. This was the first time a nuclear emergency had been declared in Japan, and 140,000 residents within $20 \mathrm{~km}$ (12 $\mathrm{mi})$ of the plant were evacuated [6]. Following the Fukushima Daiichi nuclear disaster, the International Energy Agency halved its estimate of additional nuclear generating capacity to be built by 2035 [7]. In September 2011, German engineering giant Siemens announced that it will withdraw entirely from the nuclear industry, as a response to the Fukushima nuclear disaster in Japan [8]. In the next time, Italy, France and Japan also declared to reduce the nuclear power from their energy consumption pattern.

Due to the problems of fossil fuels and erratic behavior of nuclear power plant, the world has been turning to alternatives of fossil fuels and nuclear energy. Renewable energies have received increasing attention as alternatives of fossil fuels and nuclear energy. Among the several renewable energies, wind energy is the most promising renewable source and it is one of the fastest growing sources of electricity at present [9]. According to the half year report 2012 of the World Wind Energy Association (WWEA), the worldwide wind capacity reached $254 \mathrm{GW}$ by the end of June 2012. The total installed wind capacity is 
expected to reach $273 \mathrm{GW}$ by the end of the year 2012 [10]. Thus, around $2.5 \%$ of global electricity consumption has come from wind turbines. Wind is a plentiful source available in the nature, widely distributed, produces no emissions during operation. In the last two decades, the wind power prospective has been studied in many countries worldwide [11]. Though wind energy is a pollution-free and inexhaustible source, it has some problems. Wind energy is a fluctuating resource which can diverge quickly. As a result, wind power is not constant and can fluctuate significantly since wind power is proportional to the cube of the wind speed. The problems originated by the wind power fluctuations are as follows [12]:

- Wind power fluctuations may cause the grid frequency to fluctuate.

- The deviation in wind speed causes the fluctuation of the active power generation and thus the wrapped up reactive power, leading to voltage flicker at the buses of the power grid.

- Frequency fluctuation and voltage flicker deliver a poor power quality and create instability problems in the power system, especially when there are loads sensitive to accept high voltage and frequency variations.

To overcome these problems, various power smoothing methods for the wind energy conversion system (WECS) have been proposed in the last decade. Based on the different power smoothing approaches, the power smoothing methods of the WECS can be divided into two categories-energy storage based power smoothing method and without energy storage based power smoothing method. Several literatures have been proposed to generate a smooth output power of the WECS with energy storage devices. Installation and maintenance costs of these devices are very high. Therefore, the recent trends of the power smoothing methods are considered without energy storage devices, and proposed some approaches to reduce the power smoothing cost of the WECS. Operating principles of different power smoothing methods are reviewed in this paper.

\section{Wind Energy Conversion System}

Due to the variable wind velocity, the variable speed wind turbine (VSWT) is the most important in the WECS because it can utilize the wind energy proficiently. Doubly fed induction generators (DFIGs) and permanent magnet synchronous generators (PMSGs) based VSWTs are the most popular for the modern wind farm. The system diagram of wind generation system is shown in Fig. 1. The PMSG based WECS is shown in Fig 1(a). The PMSG can omit the gearbox. Hence, it can release all difficulties of the gear box. Wind energy obtained from the wind turbine is sent to the generator. The rotational speed of the PMSG is controlled by a pulse width modulation (PWM) converter. The output power of the PMSG is supplied to the grid through a generatorside converter and a grid side inverter. The system diagram of the DFIG based WECS is shown in Fig. 1(b). The stator of the DFIG is directly connected to the grid, while a back-to-back three-phase voltage source PWM inverter controls the rotor, which, in turn, is connected to the grid on the other side.

Wind turbine output power, $P \mathcal{w}$, and wind turbine torque, $T w$, are given by the following equations:

$$
\begin{aligned}
& P_{w}=\frac{1}{2} C_{p}(\lambda, \beta) \rho \pi R^{2} V_{w}^{3} \\
& T_{w}=\frac{1}{2} C_{p}(\lambda, \beta) \rho \pi R^{3} V_{w}^{2} / \lambda
\end{aligned}
$$

where $V w$ is the wind speed, $\rho$ is the air density, $R$ is the wind turbine blade radius, $\omega_{\mathrm{w}}$ is the angular speed of the wind turbine, $C p$ is the power coefficient, $\lambda$ is the tip speed ratio, can be defined as $\lambda=\left(\mathrm{R}_{\mathrm{o}} \omega_{\mathrm{w}}\right) / \mathrm{V}_{\mathrm{w}}, \omega_{\mathrm{w}}$ is the angular speed of the wind turbine and $\beta$ is the pitch angle.
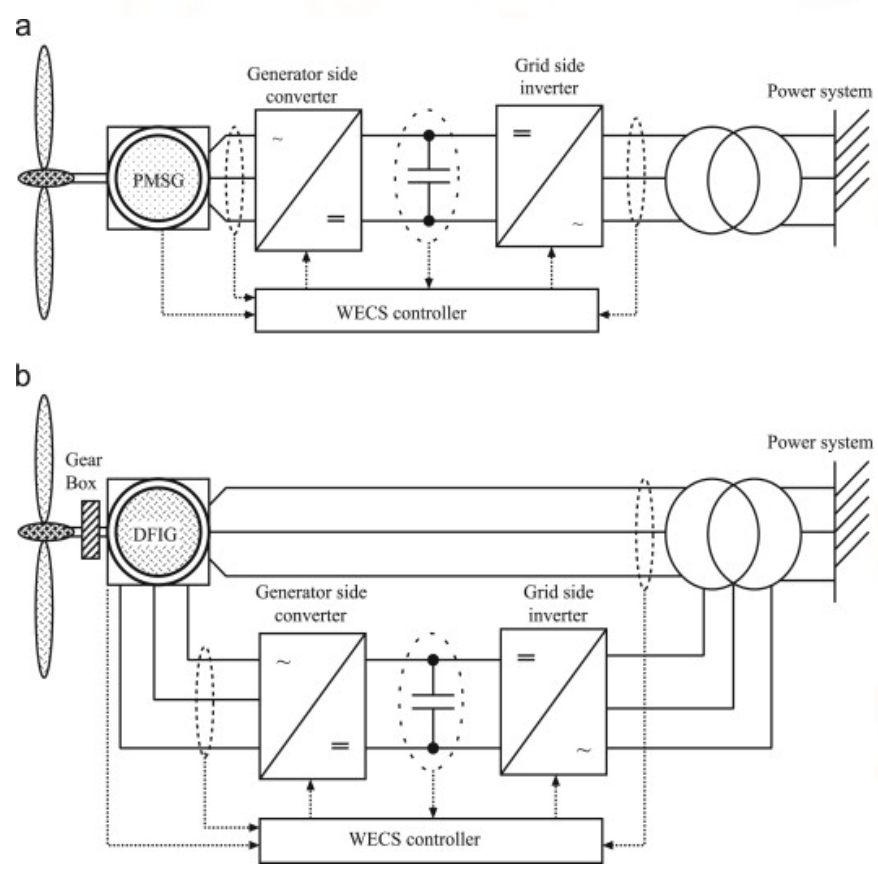

Fig -1 Wind energy conversion system (a) PMSG based wind turbine, (b) DFIG based wind turbine. 


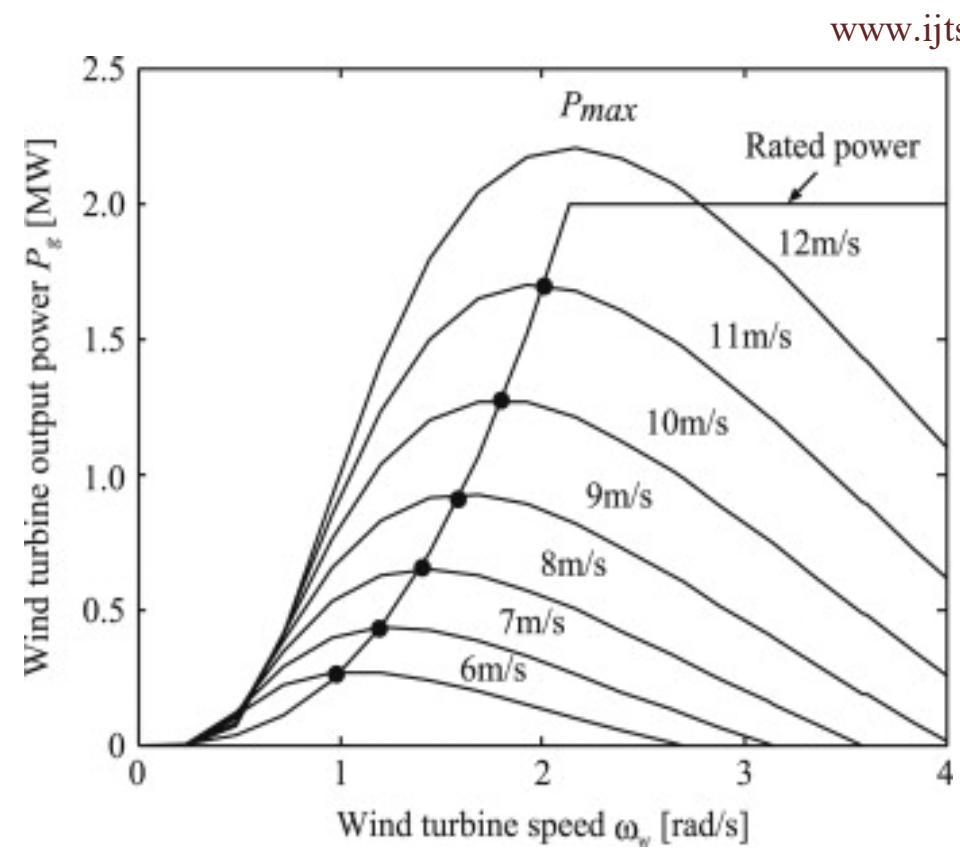

Fig -2 WECS output power characteristics.

The output power characteristics of the wind turbine are depicted in Fig. 2. Here the pitch angle is $\beta=2^{\circ}$. From this figure, it can be seen that there is a rotational speed, $\omega_{\text {opt }}$, dotted by the black circles, for any particular wind speed. $\omega_{o p t}$ is called the optimum rotational speed and generates the maximum power, $P_{\max }$. In this way, the maximum power point tracking (MPPT) control to each wind speed can increase the power generation for the VSWTs. The value of $\omega_{o p} t$ is calculated by differentiating $C p$ with respect to $\omega_{\mathrm{w}}$.

\section{Power Smoothing Methods}

The major categories of power smoothing methods of the WECS are shown in Fig. 3. There are two foremost types of power smoothing methods such as energy storage based power smoothing methods and without energy storage based power smoothing methods.

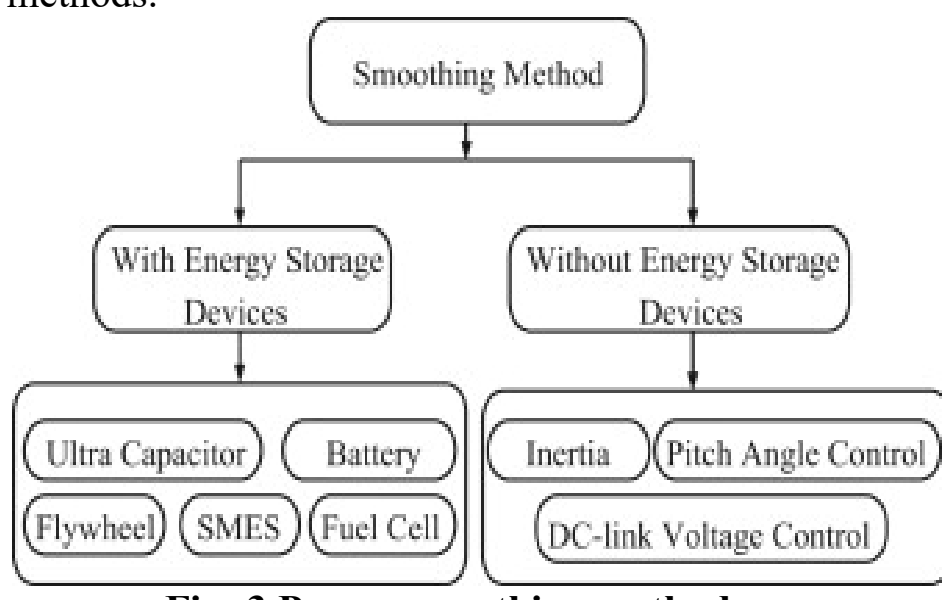

Fig -3 Power smoothing methods.

\subsection{Energy storage based power smoothing} methods

In this subsection, power smoothing techniques of the WECS using different energy storage devices are described. The algorithms of the energy storage based power smoothing methods are almost similar to each others. Power smoothing topologies of the ultra capacitor, battery and SMES are identical, fuel cell and flywheel systems are slightly different. The power smoothing methods are described as follows.

\subsubsection{Ultra capacitor, battery and SMES based power smoothing}

The energy storage system i.e. ultra capacitor, battery or SMES based power smoothing method is shown in Fig. 4(a) and (b). Fig. 4(a) shows that the energy storage is connected to the DC-link of the frequency converter of the generator. This topology does not require the bi-directional voltage source inverter (VSI) and needs only a buck-boost DC-DC converter to control the realpower which can reduce the system cost. But it is quite appropriate for a stand-alone system. If this system is applied to the wind farm which is composed of multiple wind turbines, the energy storage system needs to be installed at each wind turbine and controlled for smoothing the line power.
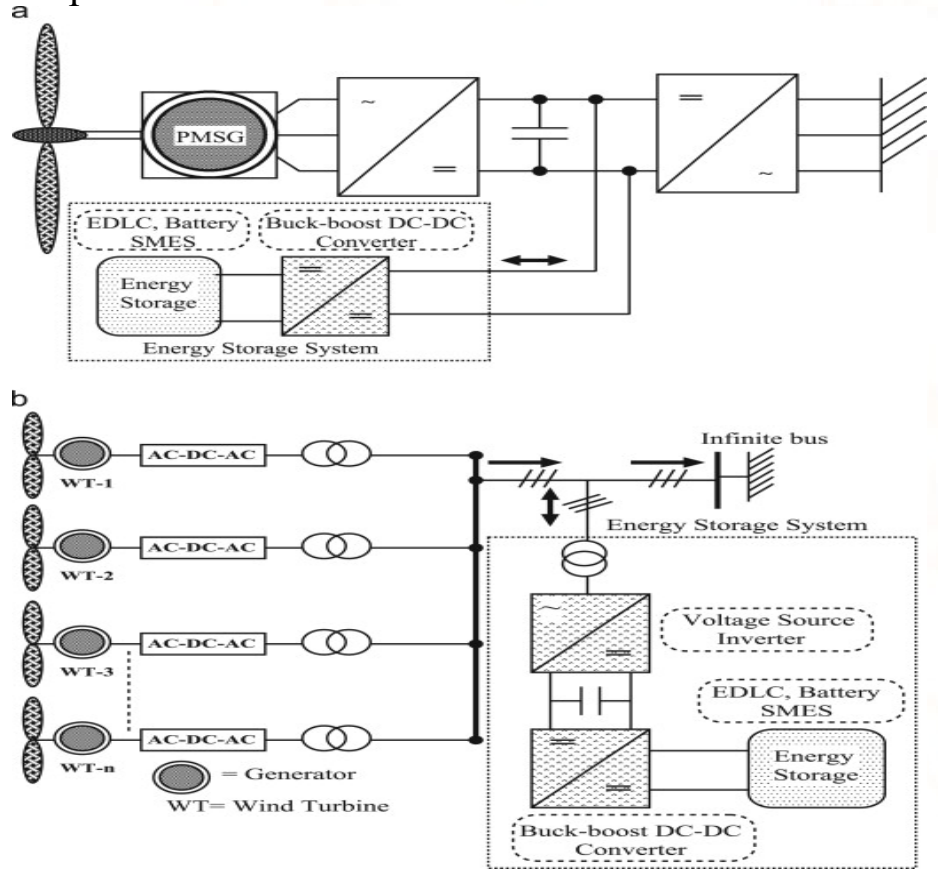

Fig. 4 ESS based power smoothing. (a) ESS connected to DC link for stand-alone system, (b) ESS connected to wind farm terminal. 
The control strategy of the each energy system will become very complicated. Considering this fact, relatively cost-effective topology for the power smoothing of the wind farm is proposed in Fig. 4(b). From this figure, the energy storage system composed of a step down transformer, a voltage source inverter, a DC-link capacitor and a buck-boost DC-DC converter which is installed at the terminal of the wind farm. When the generated power of the wind turbine is greater than the smooth line power reference signal, the energy storage system charges and vice versa, which is ensured to deliver a smooth power to the power grid.

\subsubsection{Fuel cell based power smoothing}

The fuel cell based power smoothing method is shown in Fig. 5(a) and (b). Fig. 5(a) shows the fuel cell with electrozer which can generate hydrogen and stored in a tank. The stored hydrogen is used as the fuel for the fuel cell. Fig. 5(b) shows the power smoothing method of the reversible fuel cell. Reversible fuel cells are designed to operate in either water electrolysis mode or power generation mode. For a wind-hydrogen system that stores hydrogen energy for later conversion back to electricity, reversible fuel cells may offer cost benefits compared to separate units for hydrogen production and power generation. Reversing the electrochemical reaction within the same cell is challenging because of the technical problems of optimizing the electrode structure and composition.

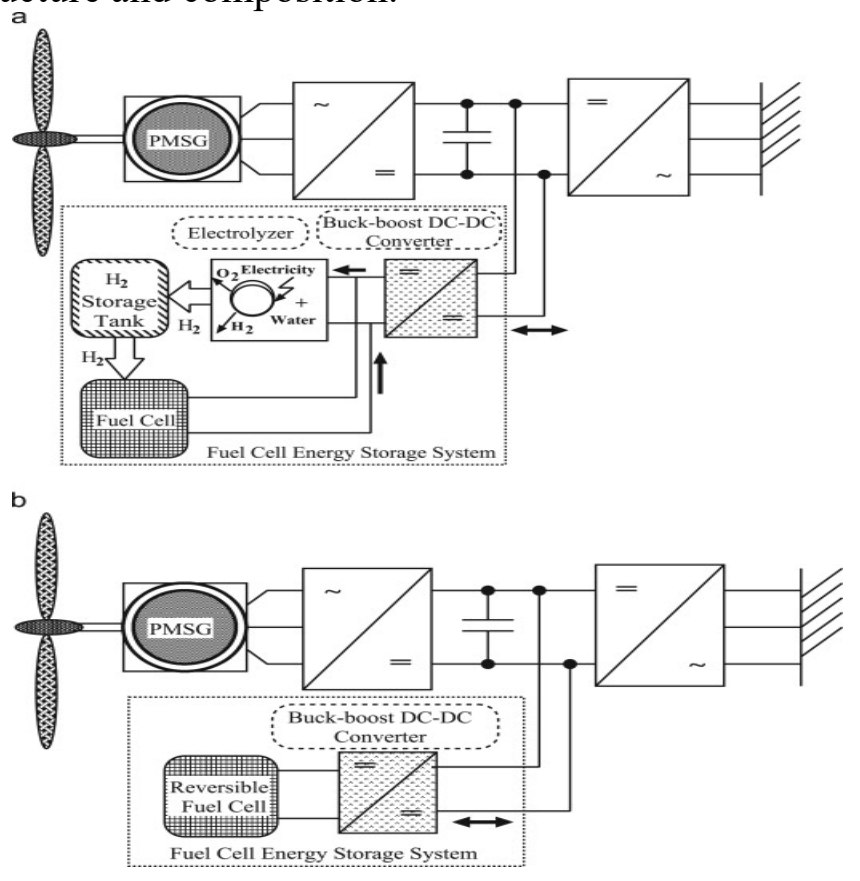

Fig. 5 Fuel cell based power smoothing. (a) Fuel cell connected to DC link for standalone system, (b) reversible fuel cell connected to DC link for stand-alone system.

\subsubsection{Flywheel based power smoothing}

In a flywheel, the storage capacity is based on the kinetic energy of a rotating disc which depends on the square of the rotational speed. A mass rotates on two magnetic bearings in order to decrease friction at high speed, coupled with an electric machine. Energy is transferred to the flywheel when the machine operates as a motor (the flywheel accelerates), charging the energy storage device. The FESS is discharged when the electric machine regenerates through the drive (slowing the flywheel). The FESS stores energy when the wind turbine generates more power, and discharges energy when wind turbine delivers less power. As a result, the wind turbine generates a smooth output power. A stand-alone FESS based power smoothing system is shown in Fig. 6(a). From this figure, the flywheel is connected to the wind turbine system through a motor and a voltage source inverter. Fig. 6(b) shows the power smoothing method for the wind farm by using the FESS. The FESS is connected to the wind farm terminal through a coupling transformer, a voltage source converter, a voltage source inverter and a motor drive. In fact, the energy stored by the flywheel is dependent on the square of the rotating speed and its inertia. In general, flywheels can be classified as low speed or high speed devices. A FESS presents suitable features regarding high efficiency (around $90 \%$ at rated power), long cycling life, wide operating temperature range, freedom from depth-of-discharge effects, higher power and higher energy density.

\subsection{Power smoothing methods without energy storage devices}

Power smoothing methods by using the energy storage devices are effective, but they impose a significant additional cost to the system. Therefore, the power smoothing methods without energy storage devices can reduce the system cost extensively. In this section, different power smoothing methods without energy storage devices are described.

1.2.1. Power smoothing by controlling the kinetic energy of the inertia 
The basic idea is to use the energy in rotor inertia to smooth the output power of the WECS. Since the kinetic energy of the wind turbine inertia is significant, it can be utilized to generate a smooth output power as an energy storage device. The concept behind this method depends on two events:

- Increase in wind turbine kinetic energy due to the acceleration of the turbine rotational speed when wind speed rapidly increases.

- A discharge of wind turbine kinetic energy due to a decline in the wind turbine rotational speed when the wind velocity drops.

a
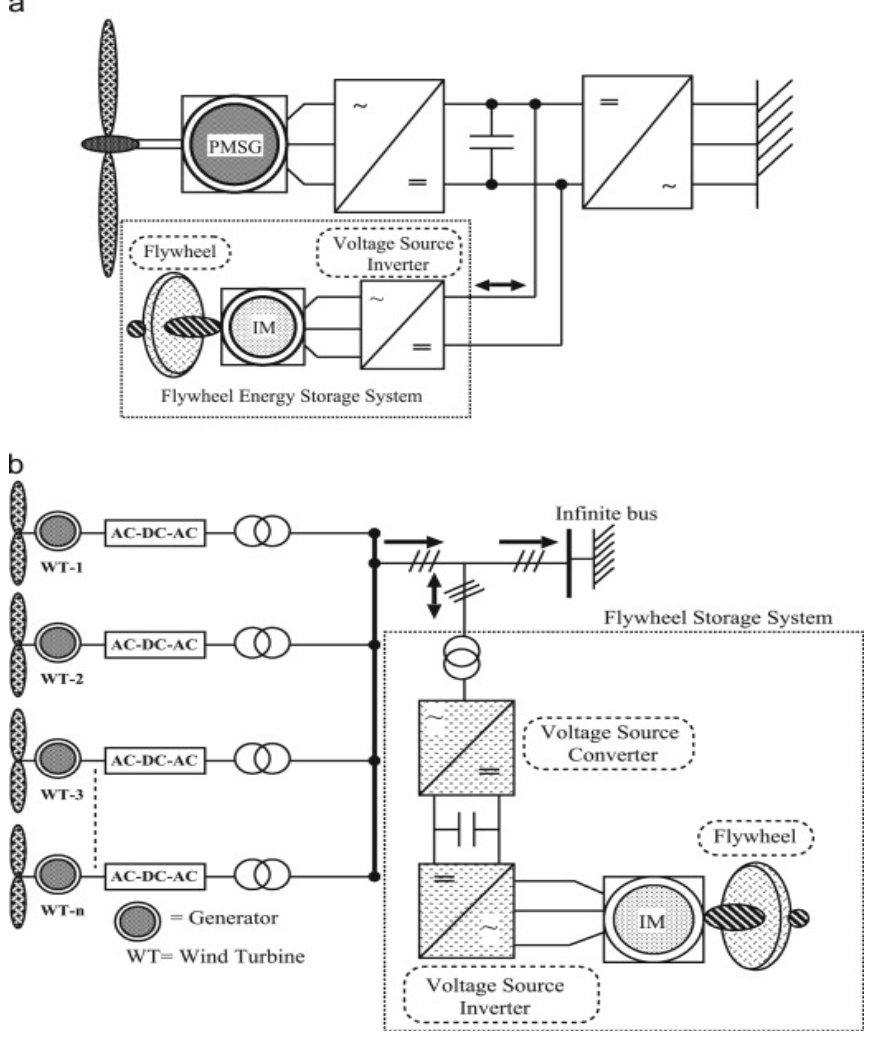

Fig.6. Flywheel based power smoothing. (a) Flywheel connected to DC link for stand-alone system, (b) flywheel connected to wind farm terminal.

\subsubsection{Power smoothing by pitch angle control system}

Pitch angle control has been one of the most common methods for smoothing at output power fluctuations during below rated wind incidents. A fuzzy logic pitch angle controller is included for smoothing wind power fluctuations during below rated wind incidents beside traditional power regulations during above rated wind incidents. The power smoothing method can generate a smooth output power of all the operating regions. Pitch angle controller with the fuzzy logic system (FLS) has advantageous in a numerous ways. Wind turbine system is highly nonlinear with many uncertain factors like meteorological conditions and continuously varying AC system loads. It also contains some unknown ambiguous dynamics which make accurate dynamic modeling of a wind turbine system difficult or even impossible.

\section{CONCLUSION}

This paper reviewed and discussed various power smoothing methods for the WECS which are still an active research area of the WECS. Due to the excessive cost of the energy storage devices, researchers have prompted to show interest in the without energy storage based power smoothing systems. Comparisons of the energy storage based power smoothing method are shown in this paper. The energy storage device can store energy and it can also restore energy to generate a smooth output power and effectively reduce the cost of energy.

\section{REFERENCES}

[1] Statistical review of world energy 2015-BP.

[2] Fossil fuels. (google.com).

[3] US Department of energy on green house gases.

[4] Nuclear energy is not a new clear resource, The world reporter.com

[5] Giugni M. "Social protest and policy change: ecology, antinuclear, and peace movements in comparative perspective". Rowman \& Littlefield; 2014.p.44, ISBN 978-0-74251827-8.

[6] Japan declare nuclear emergency, as cooling system fail sat, Power plant, Business Insider; Report 11 March 2011.

[7] Gauging the pressure, The Economist, 28 April 201.

[8] Siemens to quit nuclear industry, BBCNews, 18 September 2011. 
[9] Bhutto AW, Bazmi AA, ZahediG. "Greener energy: issues and challenges for Pakistanwind power prospective. Renewable and Sustainable Energy Reviews2013;20:519-38.

[10]Komarov D, Stupar S, Simonovic A, Stanojevic M. "Prospects of wind energy sector development in Serbia with relevant regulatory frame work overview". Renewable and Sustainable Energy Reviews 2012;16:2618-30.
[11] Ilkilic C, Turkbay I. "Determination and utilization of wind energy potential for Turkey". Renewable and Sustainable Energy Reviews 2010;14:2202-7.

[12] Chowdhury MA, Hosseinzadeh N, Shen WX. "Smoothing wind power fluctuations by fuzzy logic pitch angle controller". Renewable Energy 2012; 38: 224-33. 